\title{
On Localization Strategies of E-C Trademark Translation
}

\author{
Qian $\mathrm{Li}^{*}$ \\ Colleges of Foreign Languages and Cultures, Foreign Linguistics and Applied Linguistics \\ Sichuan University \\ Chengdu City 610000
}

\begin{abstract}
Trademark, as the identity of products, plays a very significant role in international trade. This thesis probes into problems and their roots in the process of E-C trademark translation, and tries to put forward some practical solutions to these problems based on the localization strategy of Skopostheory, thus not only helping us Chinese better understand the English trademarks, but giving some clues to the C-E trademark translation of Chinese enterprises in their going-global strategy and their attempts to capture the markets of English-speaking countries.
\end{abstract}

Keywords-E-C Trademark Translation; Sino-western Cultural Differences; Localization Strategy

\section{INTRODUCTION}

As E-C trademark translation is obviously considered as a way of cross-culture communication, it's necessary for us to deal with problems in the E-C trademark translation from the cultural aspect. However, there have been few studies on E-C trademark translation and fewer connected to cultural differences. Hence, the author in this paper plans to start with problems in E-C trademark translation, then tries to explore their roots through a comparative analysis of Sino-western cultural differences, and finally suggests applying Hans J. Vermeer's Skopos theory into practice of E-C trademark translation in order to tackle down the major problems and make the Chinese translated version of English trademark widely accepted.

\section{Two PRoblems AND THEIR RoOTS IN E-C TRADEMARK TRANSLATION}

\section{A. Problems in E-C Trademark Translation}

First, verbosity in length. It means that the Chinese translated version of trademarks contain more than four characters without particular meaning, which goes against the habit of trademark naming in Chinese, and destroyes the brevity of trademark. It has been proved that the longer the translated version of trademark is, the less popular the products would be with consumers, and vice versa. Here are some typical Chinese translated versions of English trademark. “Willam Grant”—“威廉格兰特”(whiskey); “James Brooks”“詹姆斯布鲁克斯”(whiskey); “Harley Davidson”—“哈雷戴 维森”(motorcycle); “Kloybateri”—“卡洛伊巴特拉”(jewelry); “Judith Leiber”—“朱迪斯雷博”(glasses); “Moskovskaya”- “莫斯科卡亚”(vodka); “Ezio Bellotti”- “埃奇奥拜洛 迪”(furniture). ${ }^{[1]}$ These trademarks are translated by the way of transliteration and they contain more than 4 Chinese characters. It's obvious that consumers may have difficulties memorizing them, which may hinder the sales of the product.

Second, no conformity to the Chinese rule of pronunciation. It means that the translation does not follow the general rule of Chinese pronunciation. Problems appear mainly in the following situations: Firstly, rarely used Chinese characters are used. For example, "Umbro" is a football clothing manufacturer, which has been translated into “茵宝” in Chinese. “茵” in Chinese is not a frequently used words, so people can hardly be interested in this brand. Secondly, Chinese polyphones are used. For example, "Osteoform" is a multi-mineral compound capsule manufacturer, which has been translated into “乐力” in Chinese. “乐” in Chinese could be pronounced as either "Le" or "Yue" so that it confuses consumers to a certain degree. Thirdly, holistic phonic effect is not considered. For example, "Newell Rubbermaid" is a global market selling all kinds of goods, which has been translated into “诺威屈伯德” in Chinese. Since all the five Chinese characters in the translated version of this trademark are tongue-twisted for Chinese people, how could its products be welcomed by the Chinese people?

Third, translation without considering specific Chinese cultural background. This can be interpreted in two aspects. One is mechanic translation without considering Chinese people's cognition and such a translation means nothing to Chinese consumers. For instance, "Nutrilite" is a company dealing in nutrient supplement foods. It was translated into “纽 崔莱” in Chinese. But a Chinese customer knows nothing about it from the translation “纽崔莱” though its English version "Nutrilite" means to provide nutrients. That's why this brand is popular with people in English-speaking countries but not with Chinese. Another is translation without considering China's specific period of cultural background. Taking "Opium", a perfume's trademark as an example. As is known, opium has the function of attracting people, thus making them use it quite often. So the company hopes to see their products are attractive to people as well as opium to people. However, its Chinese version “鸦片” makes Chinese think about the war between China and Britain in 1840. Because of the "Opium" (鸦片), many Chinese lost their families and their own lives, and China lost a great sum of money, antiques and even the 
sovereignty in some territories. So the translation reminds people of the miserable experience and nobody decides on such a product.

Fourth is neglecting homophones in Chinese words. In Chinese, there's an interesting phenomenon - homophoneswords with different meanings which are pronounced in the same way but are spelled differently. ${ }^{[2]}$ For example, "Sportsman", a bicycle manufacturer, was translated into “斯 波兹曼” in Chinese. However, due to the existing homophones, it's quite possible for Chinese consumers to associate “斯" and “曼” with “死” and “慢”. Another example is “Whiskey”, a strong alcoholic drink producer which was translated into “威 士忌” in Chinese. However, in Chinese, it could be natural for consumers to understand it as “威猛的士兵都需要忌 讳”(strong soldiers shouldn't drink this kind of liquor). It's apparent that both of these two products wouldn't be favored by Chinese people and so both of them are unsuccessful translated trademark.

Fifth is that the translated trademark is not appealing and too ordinary. It is admitted that Chinese people are too much concerned about keeping face, so when they buy something, they certainly want that kind of products which has an unusual name. For example, "Gillette", an American razor brand, was translated into “吉列” in Chinese. These two Chinese characters seem to be too common, so it cannot draw Chinese consumers" attention. "Converse" is a sports shoes manufacturer in the United States, and it was translated into “匡威” in Chinese. "Converse" means different from others, but in Chinese “匡威”, it means nothing but ordinary. Therefore, people do not buy them when they do not know anything about them. Surely, when they find “匡威” is preferred by some people whom they admire, they may accept it in order to show off or follow the fashion. However, "Mr. Muscle" (a household cleaners manufacturer) is quite different. Its Chinese version “威猛先生” pushes people to think that it is powerful or makes them powerful, so they may get some even when they do not know what it is.

\section{B. Roots of Problems in E-C Trademark Translation}

Differences in core cultural values. Core cultural values are the foundations of culture, which cannot be changed easily or quickly. The ultimate aim of trademark is to promote sales, which means that trademark should chiefly obey the target consumers' core cultural values. Obviously, Chinese translated version of English trademark should be in line with Chinese core cultural values. That is, special attention should be paid to differences in core cultural values when E-C trademark translation is concerned in that Chinese core cultural values are quite different from western countries' core cultural values.

In China, people pursue collectivism. It means that Chinese people hold the view - individual person's interest should comply with collective interests. People in China are more likely to concern themselves with national and family affairs, and they spend more energy to treat others well. Under such a background, Chinese people show more favor to trademarks which comprise this kind of values, for example, “万家乐”,
“老干妈”, “居安家”, etc. In western countries, people favor individualism. It means that people in western countries believe that every person should work hard to gain his or her own personality. They always put individualism in the first place when they're doing something. That is to say, they advocate more freedom. So they favor trademarks which contain this kind of values, for example, "Pioneer", "Land Rover", "Puritan's Pride", etc.

Differences in purchasing psychology. As mentioned before, purchasing psychology is a kind of mind-set pertaining to buying things; it is formed in and changes with social development. In other words, products sold in different countries will certainly be confronted with different consumers with different purchasing psychology.

According to Hellmut Schutte's Consumer Behavior in Asia, consumers in western countries who buy luxuries always think that the products are equipped with some special style or characteristics they need..$^{[3]}$ However, a big proportion of consumers in China who buy luxuries think luxuries can show that they're rich. That is to say, Chinese people pay close attention to their face. For example, the following trademarks are popular because they all satisfy Chinese people's purchasing psychology— having face: “巴黎世家”, “老佛爷 百货” and “宝马”. In western countries, people go after practicability, which greatly influences their purchasing psychology. When they buy things, they put the quality of the product and suitability above everything. "Smartwater", "Snickers" and "Hersheys" are popular with them because their brief names give consumers information of what they are or what they can bring to consumers, which conform to the purchasing psychology - practicability.

Differences in aesthetic standards. Aesthetic standards refer to a philosophical theory as to what is beautiful. One same thing perceived by different people would result in different opinions, and people from different countries have totally different aesthetic standards.

In China, there's one adage "Man's nature at birth is good". It shows that Chinese believe people are born with philanthropism. With such national traditional virtues, they are willing to accept what advocates kindness, beauty, bravery, etc. So, they tend to believe trademarks which contain words carrying these meanings, like “好丽友”, “仁和” and “惠普”. In western counties, most people are apt to pursuing the truth. In their eyes, truth counts a lot. They believe that all human beings are born with wickedness because the first human beings, Adam and Eve, disobeyed God. Hence, it is easy for people in western countries to accept trademarks which contain words showing the truth. "Clean Clear", "Facebook" and "Clinique" are among those which can gain favor of people in western countries.

Differences in language. As is known to all, Chinese belongs to Sino-Tibetan languages while English belongs to Indo-European languages. Sino-Tibetan languages is the family of tonal languages, but Indo-European language is a family of language which have no tone. They're absolutely two languages which have little in common. 
coherence rule under the Skopostheory, the Chinese translated version of English trademark should be coherent with Chinese Nation's Cultural Psychology.

A good point in case is the trademark "Kiss Me". It is made a trademark and becomes very popular simply because it expresses love so directly and gives consumers a feeling of being an attractive woman. However, it will never be accepted in China if it is literally translated as “吻我”or “爱我”, for in Chinese culture it is a virtue to control their feelings and they tend to be more conservative and introvert even if they have to express such feelings. Therefore, a good Chinese version is “骑 士 美”, which adapts to Chinese Nation's cultural psychology - pursuit of beauty, bravery and being reserved. If a man sees such a trademark, he may stop and make a purchase because he will be glad to be regarded as gentle and generous; if a lady sees it, she may hurry to see what it is and tries to get some because it will bring her beauty. In either case, it is economically beneficial to the company and this is the general skopos of trademark translation - to publicize, arouse the potential customers' interests and attract them to make a purchase. Another example is Poison, which is made a trademark because it catches the national psychology of western society - curiosity for something mysterious, pursuit of adventure and preferring to try something new or different. Without doubt, it can't be mechanically translated as “毒药” in Chinese, for it does not cater to Chinese national psychology. In Chinese，“毒药” is something that everyone tries to avoid, so with such a translated version, the company has to go bankrupt. Instead, its Chinese translation “百爱神” has made it an instant success in China though it is longer than the original one. “百爱” indicates its popularity and “神” suggests its authority, which reflects not only Chinese strong passion for beauty but their worship for the authority as well as the desire to follow the crowd, thus really fulfilling the general skopos of expanding the market and promoting the selling.

Adapting to Chinese consumer's psychology. Every minute there're many products sold, but what's the motivation for people to buy a certain product in the market from countless goods. There're so many different factors including, price, quality, service, package, etc. All of these things have a common point that they must satisfy one or more aspects of the target consumers, and trademark is a way to tell consumers whether or not the products can meet the certain need of the consumers. Based on skopos rule, the primary function of a trademark is to make consumers take out their money from their pocket to buy its products. So in E-C trademark translation, enough attention should be paid to Chinese consumers' psychology.

Take the translation of "Subway" as an example. It is translated into “赛百味” and it's well welcomed by Chinese people, for "赛百味” in Chinese means that this kind of food is more delicious than all the other foods. Just imagine if "Subway" is translated into “地铁”, which has no connection with the food, but pushes people to think of the underground means of transportation. "Pampers", a baby diapers manufacturer, was translated into“帮宝适”. “帮宝适” in Chinese means that when the baby pees, this kind of product 
can make the baby feel comfortable automatically, which saves its parents from a lot of trouble, for many women in China have their own job in the daytime and they want to have a good rest at night to work better next day. The translation “帮宝适” has caught the psychology of these Chinese parents so that it sells well. If it were translated into “盼木盼斯” in Chinese, consumers certainly won't give a glimpse of this kind of product since it means nothing and it's easy for people in China to associate “斯” with “死”. Taking "Das Auto" as another example, it's a trademark of a car manufacturer in Germany. "Das Auto" was translated into “大众”, which means that its price isn't high and every family can afford it, thus making Chinese people not show off, on one hand, but on the other hand, keep the face and practice thrift. China accounts for $40 \%$ of its share of sales in market. Obviously, “大众” can account for $40 \%$ share in Chinese market is due to the fact that its Chinese version of the brand caters to their psychology. As is known to all, Chinese people like the quality of perseverance and modesty, so these four plants “梅”(plum), “兰”(orchid), “竹”(bamboo) and “菊”(chrysanthemum) are very popular in China. All these four plants share the features of beauty, elegance but not showing off or pretension. Some translators notice this, so when they're doing E-C trademark translation, they always choose Chinese characters which can show the feeling of modesty. There're several successful examples: “兰 博基尼”, “格兰仕” and “竹之锦”.

Adapting to Chinese aesthetic habits. Aesthetic habits refer to the judgment or evaluation made by consumers toward a certain product, including a very complex series of psychological activities. Aesthetics is what all peoples dream for and pursue, just as Lin Yutang puts, "All words have their beauty of sound, beauty of conveying spirit and beauty of form such as writing force and style."[7] When it comes to trademark, it should be not only be concise and clear but also be easy for consumers to read, which gives consumers information about its product in a graceful way at the first sight and this is what Skopos rule advocates. Therefore, in the process of trademark translation, customers' aesthetic habits should be considered in order to stimulate them to buy certain products.

A good translated trademark can exert huge and profound impact on consumers, which can play the role of promoting products. For example, “Coca-Cola" was translated into “可口 可乐” which in Chinese means delicious drink. “可口可乐” gives Chinese people an aesthetic feeling of its rhymes and “乐” itself in Chinese can bring people a sense of pleasure. Besides, the four Chinese characters are easy to read and write, which brings consumers an aesthetic feeling of beauty and brevity. Another example, "Safeguard", a kind of soap, was translated into “舒肤佳” which in Chinese means that it's good at cleaning your skin and making you more comfortable. “舒肤 佳” in Chinese sounds funny, brief and resounding, thus brings an instant sensation in China. In addition, most Chinese people like characters like, “诚”, “梦”, “爱”, “想” and “美”, which are connected with Chinese traditional virtues. So they are often used in E-C trademark translation and here are several successful examples: “American standard”: “美 标”, “Simmons”: “席梦思”, “Hermès”: “爱马仕”, etc. As is known to all, in Chinese, “美” gives people a good feeling of connecting to beautiful things, “梦” leads them to think of a sweet dream, while “爱” gives them a feeling of warmth.

Adapting to Chinese language habits. Based on the Skopostheory, the basic function of a trademark is to give instructions to the consumers, which requires that a translated version of a trademark should be coherent with the target consumers' language habits, for language is the first step leading consumer to know the products. In a nutshell, in order to cater to the target consumers' language habit, the translated trademark should be suitable not only in the ways of using words, but also in pronunciation.

Take “McDonald” as an example. “麦当劳” is better than “麦克唐纳德”, for it follows Chinese language habits-a trademark usually consists of no more than four characters. Just as a saying goes, "When in Rome, do as Romans do." Another example concerns "Mercedes-Benz", a world-famous car manufacturer. It was originally translated into “梅赛德斯-奔 驰”, but in Chinese consumers view, it is too long, so they just take its short form “奔驰”, which does not change the brand but keeps the original association-running very fast and proving very cool. Interestingly, this has been noticed by the manufacturer and its trademark is later made Benz. "Crest", a kind of toothpaste, is another example. Its Chinese version “佳 洁士” consists of three characters, which makes people not only pronounce them easily, but also feel clear and melodious. As is known to all, Chinese is a language with much attention to tones. In their eyes, the high tones make things sound sonorous and bring the magnificence and grandeur. Hence, those trademarks with high tones can attract them. “宝马” and “奥迪” both have their great market share in China, but “奥迪” is more popular in China nowadays. Maybe one of the chief reasons is that “奥迪” contains two high-tone characters while “宝马” contains only one, though “宝马” is also a typical successful translation, which follows the skopos rule-with the customers as the focus and the only purpose. The translation catches the Chinese people's psychology by using the beautiful loving word “宝” and follows Chinese tradition culture by using “马”, which has been regarded as a very important and an irreplaceable means of transportation.

\section{CONCLUSION}

This thesis has made a thorough analysis of problems in E$\mathrm{C}$ trademark translation and their roots from cultural differences. With the problems and their reasons, the author has put forward the localization strategy under the guidance of the Skopostheory, and suggested the specific methods like (1) adapting to Chinese nation's cultural psychology, (2) adapting to Chinese consumer's psychology, (3) adapting to different aesthetic habits and (4)adapting to different language habits. 


\section{REFERENCES}

[1] Xu Ping, On the Trademark Language and Its Translation Strategy, Legend Biography Literary Journal Selection, vol. 3, pp. 56-60, 2012. (In Chinese)

[2] Oxford Advanced Learner's English-Chinese Dictionary, Beijing: The Commercial Press, p.981, 2009.

[3] S. Hellmut, Consumer Behavior in Asia, New York: New York University Press, 1998, pp.3-5.
[4] Cheng Feng, The Translation of Trade Names on View of Principle of Equivalence, vol. 10, pp.120-122, 2004.(In Chinese)

[5] H. J. Vermeer, A Skopos Theory of Translation, Textcon Text Verlag, 1996, pp.10-18.

[6] E. Nida, Language, Culture, and Translating, Shanhai: Shanhai Foreign Language Education Press, 1993, pp.79-82.

[7] Li Dongqi, Localization of Trademark Translation, Journal of Tonghua Normal University, vol. 3, pp. 63-65, 2010. (In Chinese) 